\title{
Spontaneous Entrainment of Running Cadence to Music Tempo
}

\author{
Edith Van Dyck ${ }^{1 *}$, Bart Moens ${ }^{1}$, Jeska Buhmann ${ }^{1}$, Michiel Demey ${ }^{1}$, Esther Coorevits ${ }^{1}$, Simone Dalla Bella ${ }^{2}$ \\ and Marc Leman ${ }^{1}$
}

\begin{abstract}
Background: Since accumulating evidence suggests that step rate is strongly associated with running-related injuries, it is important for runners to exercise at an appropriate running cadence. As music tempo has been shown to be capable of impacting exercise performance of repetitive endurance activities, it might also serve as a means to (re)shape running cadence. The aim of this study was to validate the impact of music tempo on running cadence.

Methods: Sixteen recreational runners ran four laps of $200 \mathrm{~m}$ (i.e. $800 \mathrm{~m}$ in total); this task was repeated 11 times with a short break in between each four-lap sequence. During the first lap of a sequence, participants ran at a self-paced tempo without musical accompaniment. Running cadence of the first lap was registered, and during the second lap, music with a tempo matching the assessed cadence was played. In the final two laps, the music tempo was either increased/decreased by $3.00,2.50,2.00,1.50$, or $1.00 \%$ or was kept stable. This range was chosen since the aim of this study was to test spontaneous entrainment (an average person can distinguish tempo variations of about $4 \%)$. Each participant performed all conditions.
\end{abstract}

Results: Imperceptible shifts in musical tempi in proportion to the runner's self-paced running tempo significantly influenced running cadence $(p<.001)$. Contrasts revealed a linear relation between the tempo conditions and adaptation in running cadence $(p<.001)$. In addition, a significant effect of condition on the level of entrainment was revealed $(p<.05)$, which suggests that maximal effects of music tempo on running cadence can only be obtained up to a certain level of tempo modification. Finally, significantly higher levels of tempo entrainment were found for female participants compared to their male counterparts $(p<.05)$.

Conclusions: The applicable contribution of these novel findings is that music tempo could serve as an unprompted means to impact running cadence. As increases in step rate may prove beneficial in the prevention and treatment of common running-related injuries, this finding could be especially relevant for treatment purposes, such as exercise prescription and gait retraining.

\section{Key Points:}

- Music tempo can spontaneously impact running cadence.

- A basin for unsolicited entrainment of running cadence to music tempo was discovered.

- The effect of music tempo on running cadence proves to be stronger for women than for men.

\footnotetext{
* Correspondence: edith.vandyck@ugent.be

${ }^{1}$ IPEM, Department of Arts, Music and Theatre Sciences, Ghent University, Technicum Blok 2, Sint-Pietersnieuwstraat 41, Ghent, Belgium

Full list of author information is available at the end of the article
}

\section{Springer}

(c) 2015 Van Dyck et al. This is an Open Access article distributed under the terms of the Creative Commons Attribution License (http://creativecommons.org/licenses/by/4.0), which permits unrestricted use, distribution, and reproduction in any medium, provided the original work is properly credited. 


\section{Background}

Approximately $56 \%$ of recreational runners sustain a running-related injury each year [1]. About $50 \%$ of all running-related injuries occurs at the knee and is most often due to the inability of the lower extremity joints to adequately control the loads applied during initial stance [2-4]. A number of strategies designed to reduce loads to these joints have been suggested, with one of the most common ones applying an increased step rate. Subtle increases in step rate have for instance been shown to substantially reduce the loading to the hip and knee joints during running and may therefore prove beneficial in the prevention and treatment of common runningrelated injuries [5]. However, less is known about the specific strategies that can be employed to change step rate. In this study, a novel strategy using music as a tool to impact step rate is examined. The means by which music might serve as an adequate tool for manipulating running cadence is discussed below.

A great deal of runners exercise while listening to music. This should not come as a surprise, since music listening during sport activities is believed to capture attention [6], distract from fatigue and discomfort [7], prompt and alter mood states [8,9], enhance work output [10, 11], increase arousal [12], relieve stress [13], stimulate rhythmic movement [14], and evoke a sense of power and produce power-related cognition and behaviour [15]. Simpson and Karageorghis [16], for instance, examined the effect of music on a $400-\mathrm{m}$ sprint performance while controlling for pre-performance mood. It was shown that music resulted in better sprint performance compared to the no music control. In another study, Styns et al. [17] observed that participants walked faster with music than with metronome ticks, while Bood et al. [18] showed that time to exhaustion was significantly longer with acoustic stimuli than without when participants were asked to run to exhaustion on a treadmill. Results of studies such as these suggest that music could be applied to physical activities, such as walking or running, with a considerable positive effect.

The idea that music can serve as a strategy for coping with physical exertion has been linked to the parallel processing model, which focuses on the limited human attention capacity $[19,20]$. This implies that the focus of an exerciser is shifted to external events in an effort to reduce the perception of neural exertion signals coming from the muscles, joints, and cardiopulmonary systems [21]. However, it appears that external musical cues can only be the focus of attention in the case of lowto-moderate physiological awareness and perceived exertion. When the workload becomes too high, the exerciser's attention is typically shifted towards the painful or fatiguing effects of the exercise [19, 20, 22-24]. In general, music has shown to be most effective to exert ergogenic and distractive effects when it is used to accompany self-paced exercise [8, 25-27]. In addition, it is believed that particularly motivational music can successfully uplift mood state and increase work capacity $[9,28,29]$.

Besides the motivational factor, exercise that is repetitive in nature is believed to benefit mostly from music that is synchronized with the tempo of the exerciser's movements; endurance can be extended, and performers exercise at higher intensities when moving in synchrony with musical stimuli [29]. It has been suggested that this effect of synchronized music is due to its ability to reduce the metabolic cost of exercise by enhancing neuromuscular or metabolic efficiency [28, 30]. Regular corporeal patterns demand less energy to imitate, due to the lack of timely adjustments within the kinetic pattern but also because of an increased level of relaxation resulting from the precise expectancy of the forthcoming movement [31]. As such, a point of reference is created that is able to attract and swiftly entrain recurring motor pattern efficiency [30, 32]. Synchronization is typically understood as an intentional mechanism, which is highly task constrained [33]. Most previous research on the impact of synchronized music on exercise performance generally focused on instructed or imposed synchronization, e.g. [12, 16-18, 29]. However, it is also the case that synchronization can occur spontaneously [33]. Previous studies have highlighted the natural or spontaneous predisposition of humans to respond to rhythmical qualities of music [34, 35], but much less is known about the capabilities of exercisers, and especially runners, to spontaneously synchronize with the tempo of musical stimuli. Yet, spontaneous entrainment of one tempo with another is only believed to occur when the strength of the coupling is able to overcome possible contrasts in natural movement period or tempo [36]. For a given coupling strength, unintentional entrainment only occurs within a specific range of period differences, reflecting the system's entrainment basin [33, 37-40].

The effect of music on repetitive endurance activities also depends on the specific tempo of the musical stimulus. Waterhouse et al. [41] revealed that cyclists' covered distance, power, and pedal cadence increased when faster music was presented, while slowing down the music tempo resulted in decreases of these measures. Edworthy and Waring [8] explored the effect of music tempo (and loudness) on treadmill running and demonstrated that an increase in the tempo, and to a lesser extent the loudness of the stimulus, resulted in an increase in running speed. In the light of findings such as those described above, it is quite plausible that music tempo could also serve as a means to influence running cadence. And as a link between step rate and hip and knee joint loading has been established before [5], results of this study 
could be particularly relevant with regard to the prevention and treatment of running-related injuries.

The aim of this study was to validate the impact of music tempo on running cadence. We hypothesized that recreational runners would adapt their self-paced running cadence to imperceptible changes in musical tempi and, thus, entrain spontaneously with the music tempo. Furthermore, we believed that the degree of entrainment would decrease with increasing changes in music tempo and, thus, that a basin for unintentional entrainment of running cadence to music tempo exists. As it has been shown that unintentional coordination typically manifests as relative or intermittent coordination (i.e. movements are attracted to a 0 or $180^{\circ}$ but are not phase locked) [36, 37, 42], rather than phase-locked steps, entrainment refers to the amount of steps taken in a tempo sufficiently close to the music tempo (max. $1 \%$ difference between running cadence and music tempo). Besides, since previous research often reported better results for women compared to men regarding music-tomovement coordination [11, 43], we expected female participants to display larger levels of entrainment. Finally, as it has been demonstrated that only when physiological awareness and perceived exertion are relatively low that music can distract from fatigue and discomfort $[19,22]$, the relationship between the level of entrainment and the degree of perceived exertion was examined.

\section{Methods}

\section{Ethics Statement}

The study was approved by the Ethics Committee of the Faculty of Arts and Philosophy of Ghent University, and all procedures followed were in accordance with the statements of the Declaration of Helsinki. In addition, all participants signed a form to declare that they participated voluntarily; that they had received sufficient information concerning the tasks, the procedures, and the technologies used; that they had the opportunity to ask questions; and that they were aware of the fact that running movements were measured, for scientific and educational purposes only.

\section{Participants}

To establish sample size, a power analysis for a repeated-measures design was conducted using $G$ *Power 3.1.9.2 [44]. Based on the effect sizes reported in comparable studies $[16,18,28]$, the analysis indicated that minimally 14 participants for an $\alpha$ of 0.05 and a power of 0.80 would be required. Sixteen healthy adult participants (nine females) took part in the study. The test group consisted of recreational runners with an average age of 22.25 years $(\mathrm{SD}=2.14)$, a mean body mass of $66.56 \mathrm{~kg}(\mathrm{SD}=9.32)$, and an average height of $1.74 \mathrm{~m}(\mathrm{SD}=0.10)$, who reported to be fit to run about $10 \mathrm{~km}$. The majority $(62.50 \%)$ had received musical training (Fisher's exact test showed no significant association between gender and musical background, $X^{2}(1)=2.05, p=.30$ ). All participants reported that running is an activity that forms a part of their lives, with varying degrees of frequency (12.50\% runs multiple times a week; $56.25 \%$ runs about once a week; $31.25 \%$ runs about once a month; $0 \%$ runs about once a year or not at all). Of all participants, $50 \%$ reported to typically train with music, $32.25 \%$ generally runs without music, and $18.75 \%$ runs both with and without musical accompaniment.

\section{Stimuli}

Previous research indicated that the natural running cadence for recreational runners lies somewhere between 130 and 200 steps per minute (SPM) [45]. On that account, a music database consisting of songs in the tempo range of 130-200 beats per minute (BPM) was created. A group of 19 students from Ghent University, all recreational runners, were asked to provide a list of at least ten songs they believed to be motivational to run to. From that specific list of music, the database for the experiment was created. In total, 117 songs with a clear beat and correct tempo range were pre-selected (see Table 1). In the course of the selection process, it was verified that the tempo of each song remained stable throughout the entire track. Using Audacity software (http://audacity.sourceforge.net), intros without clear beats were cut from the stimuli. BeatRoot [46] was applied to track the beats of each song in order to ensure that only songs between 130 and 200 BPM were included, while ReplayGain was used to normalize perceived loudness and minimize possible imbalances in sound pressure level.

\section{Apparatus}

Participants were equipped with two iPods (fourth generation), one attached at each ankle. Using the Sensor Monitor Pro application on the iPods, data from accelerometers and gyroscopes was streamed wirelessly at $100 \mathrm{~Hz}$ to the main processing computer. A Wi-Fi hotspot (TP-Link N750) with special 3-dB gain antennas for longer range was used for maintaining a stable connection between the computer and sensors. Some minimal jitter and lag in the data stream were neutralized using a $500-\mathrm{ms}$ buffer before processing.

Incoming sensor data was processed by a customized version of D-Jogger [47], a music alignment framework that selects and tempo-adapts music to runners' gait frequencies using kinematic sensor input (Additional file 1). Music tempi were manipulated using a phase vocoder, which time stretches music without pitch 
Table 1 List of musical stimuli

\begin{tabular}{|c|c|c|c|c|c|}
\hline ID & Artist & Song & Label(s) & Year published & Tempo (BPM) \\
\hline 1 & Epica & Illusive Consensus & Transmission & 2003 & 132 \\
\hline 2 & Gregory Porter & On My Way to Harlem (Radio Edit) & Motema & 2012 & 138 \\
\hline 3 & Interpol & Slow Hands & Matador & 2004 & 139 \\
\hline 4 & The Supremes & I Hear a Symphony & Motown & 1965 & 139 \\
\hline 5 & Van Halen & Ain't Talkin' 'Bout Love & Warner Bros & 1978 & 139 \\
\hline 6 & Combichrist & Electrohead & Out of Line/Metropolis & 2007 & 140 \\
\hline 7 & dEUS & The Soft Fall & PIAS & 2012 & 140 \\
\hline 8 & P!nk & Who Knew & LaFace & 2006 & 140 \\
\hline 9 & Noisettes & Never Forget You & Mercury/Nertigo & 2009 & 141 \\
\hline 10 & Rammstein & Benzin & Motor & 2005 & 142 \\
\hline 11 & Royksopp & Tricky Tricky & Astralwerk/EMI & 2009 & 142 \\
\hline 12 & Deftones & My Own Summer (Shove It) & Maverick/Warner Bros & 1997 & 143 \\
\hline 13 & 16 Horsepower & Outlaw Song & Jetset & 2006 & 144 \\
\hline 14 & Coldplay & In My Place & Parlophone & 2002 & 144 \\
\hline 15 & The Hickey Underworld & Future Words & PIAS & 2009 & 145 \\
\hline 16 & ABBA & Waterloo (English Version) & Polar/Epic & 1973 & 146 \\
\hline 17 & Steppenwolf & Born to Be Wild & Dunhill/RCA & 1967 & 146 \\
\hline 18 & The Sisters of Mercy & Alice & Merciful Release & 1982 & 146 \\
\hline 19 & School Is Cool & The World Is Gonna End Tonight & Not on label & 2011 & 147 \\
\hline 20 & Tom Odell & I Know & Columbia/In the Name Of & 2012 & 147 \\
\hline 21 & Trixie Whitley & Irene & Unday Records & 2013 & 147 \\
\hline 22 & Aphex Twin & Flim & Warp/Sire/WEA & 1997 & 148 \\
\hline 23 & Bruce Springsteen & Dancing In the Dark & Columbia & 1984 & 148 \\
\hline 24 & Nneka & Heartbeat & Yo Mama's Recording & 2008 & 148 \\
\hline 25 & Alt-J & Breezeblocks & Infectious & 2012 & 149 \\
\hline 26 & Marco Borsato & Ik leef niet meer voor jou & Polydor & 1995 & 149 \\
\hline 27 & A Perfect Circle & Thinking of You & Virgin & 2000 & 150 \\
\hline 28 & Editors & An End Has a Start & Kitchenware/FADER & 2007 & 150 \\
\hline 29 & Florence and The Machine & Dog Days Are Over & Island & 2009 & 150 \\
\hline 30 & Guns N' Roses & It's So Easy & Geffen Records/Interscope & 1987 & 150 \\
\hline 31 & Katy Perry & E.T. & Capitol & 2010 & 150 \\
\hline 32 & Pearl Jam & Lightning Bolt & Monkeywrench/Republic & 2013 & 151 \\
\hline 33 & The Killers & Spaceman & Island/Nertigo & 2008 & 151 \\
\hline 34 & Bloc Party & Flux & Wichita/Nice & 2007 & 152 \\
\hline 35 & Elton John & Saturday Night's Alright (For Fighting) & MCA/DJM & 1973 & 152 \\
\hline 36 & P!nk & Are We All We Are & RCA & 2012 & 152 \\
\hline 37 & De Staat & Sweatshop & Cool Green Recordings & 2011 & 153 \\
\hline 38 & Ike \& Tina Turner & Nutbush City Limits & United Artists & 1973 & 153 \\
\hline 39 & Kings of Leon & Sex On Fire & $\mathrm{RCA}$ & 2008 & 153 \\
\hline 40 & OutKast & B.O.B. & LaFace/Arista & 2000 & 153 \\
\hline 41 & The Black Eyed Peas & Pump It & Interscope & 2005 & 153 \\
\hline 42 & Massive Attack & Teardrop & Circa/Virgin & 1998 & 154 \\
\hline 43 & Kaiser Chiefs & Never Miss a Beat & B-Unique/Universal & 2008 & 155 \\
\hline 44 & Morphine & Honey White & Rykodisc & 1995 & 155 \\
\hline
\end{tabular}


Table 1 List of musical stimuli (Continued)

\begin{tabular}{|c|c|c|c|c|c|}
\hline 45 & The Pipettes & Your Kisses Are Wasted On Me & Memphis Industries/Cherrytree & 2006 & 155 \\
\hline 46 & The Strokes & Juicebox & $\mathrm{RCA}$ & 2006 & 155 \\
\hline 47 & Hooverphonic & Mad About You (Orchestra Version) & Columbia & 2012 & 156 \\
\hline 48 & Nirvana & In Bloom & DGC & 1991 & 156 \\
\hline 49 & The Van Jets & Ricochet & Belvédère & 2005 & 156 \\
\hline 50 & Air & Surfing On a Rocket & Virgin & 2004 & 157 \\
\hline 51 & Millencolin & No Cigar & Epitaph & 2000 & 157 \\
\hline 52 & The Beach Boys & Surfin' USA & Capitol & 1963 & 157 \\
\hline 53 & Shaggy & Boombastic & Virgin & 1995 & 158 \\
\hline 54 & Jones \& Stephenson & The First Rebirth (Original Mix) & Prolekult & 1994 & 159 \\
\hline 55 & Kings of Leon & California Waiting & RCA/HandMeDown & 2003 & 159 \\
\hline 56 & Michael Sembello & Maniac & Warner Bros & 1983 & 159 \\
\hline 57 & OutKast & Hey Ya! (Radio Mix Club Mix) & LaFace & 2003 & 159 \\
\hline 58 & Beyonce & Halo & Columbia & 2008 & 160 \\
\hline 59 & Birdman \& Lil Wayne & Stuntin' Like My Daddy (Street) & Cash Money/Universal & 2006 & 160 \\
\hline 60 & Customs & Justine & Noisesome/EMl & 2009 & 160 \\
\hline 61 & Mastodon & Spectrelight & Reprise/Roadrunner & 2011 & 160 \\
\hline 62 & TNGHT & Higher Ground & Warp/LuckyMe & 2012 & 160 \\
\hline 63 & P.O.D. & Alive & Atlantic & 2001 & 161 \\
\hline 64 & Queens of the Stone Age & Little Sister & Interscope & 2005 & 161 \\
\hline 65 & 'T Hof Van Commerce & Baes (Radio Edit) & Plasticine & 2012 & 162 \\
\hline 66 & Black Sabbath & Paranoid & Vertigo & 1970 & 162 \\
\hline 67 & Blondie & One Way or Another & Chrysalis & 1978 & 162 \\
\hline 68 & Karate & Ice or Ground & Southern & 2002 & 162 \\
\hline 69 & Moby & Feeling So Real & Mute/Elektra & 1995 & 162 \\
\hline 70 & Orchestral Manoeuvres In the Dark & Electricity & Factory & 1979 & 162 \\
\hline 71 & U96 & Love Religion (Video Edit) & Guppy/Motor & 1995 & 162 \\
\hline 72 & Wham! & Wake Me Up Before You GoGo & Columbia & 1984 & 162 \\
\hline 73 & Bomfunk MC's & Freestyler & Sony Music Finland/Epidrome & 1999 & 163 \\
\hline 74 & Jamaica & Cross the Fader & Downtown & 2011 & 164 \\
\hline 75 & Midlake & Antiphon & Bella Union & 2013 & 164 \\
\hline 76 & Muse & Survival & Helium 3/Warner Music Group & 2012 & 164 \\
\hline 77 & Sugababes & About You Now & Island & 2007 & 164 \\
\hline 78 & Ella Fitzgerald & A-Tisket, A-Tasket & Golden Options & 2008 & 165 \\
\hline 79 & Ike \& Tina Turner & River Deep Mountain High & Philes & 1966 & 165 \\
\hline 80 & Green Day & Boulevard of Broken Dreams & Reprise & 2004 & 166 \\
\hline 81 & Pixies & Where Is My Mind & $4 A D$ & 1988 & 166 \\
\hline 82 & Rammstein & Mann gegen Mann & Universal & 2005 & 166 \\
\hline 83 & Arctic Monkeys & Do I Wanna Know & Domino & 2013 & 170 \\
\hline 84 & Chet Faker & I'm Into You & Opulent/Remote Control & 2012 & 170 \\
\hline 85 & Joy Division & Disorder & Factory & 1979 & 170 \\
\hline 86 & Panic! At the Disco & I Write Sins Not Tragedies & Fueled by Ramen/Decaydance & 2005 & 170 \\
\hline 87 & Queens of the Stone Age & No One Knows & Interscope & 2002 & 170 \\
\hline 88 & The All-American Rejects & My Paper Heart & Doghouse/DreamWorks & 2002 & 170 \\
\hline 89 & Foo Fighters & The Pretender & Roswell/RCA & 2007 & 172 \\
\hline
\end{tabular}


Table 1 List of musical stimuli (Continued)

\begin{tabular}{|c|c|c|c|c|c|}
\hline 90 & Netsky & Love Has Gone & Hospital & 2012 & 172 \\
\hline 91 & Paramore & Misery Business & Fueled by Ramen & 2007 & 172 \\
\hline 92 & The Streets & Fit But You Know It & Locked On/679 & 2004 & 172 \\
\hline 93 & DJ Fresh & Hot Right Now (Radio Edit) & Ministry of Sound & 2012 & 174 \\
\hline 94 & Interpol & A Time To Be So Small & Matador & 2004 & 174 \\
\hline 95 & Kanye West & Homecoming (feat. Chris Martin) & Roc-A-Fella/Def Jam & 2008 & 174 \\
\hline 96 & Rudimental & Waiting All Night (feat. Ella Eyre) & Asylum & 2013 & 174 \\
\hline 97 & Kelis \& Andre 3000 & Millionaire & Virgin & 2004 & 176 \\
\hline 98 & Technohead & I Wanna Be a Hippy & Mokum & 1995 & 177 \\
\hline 99 & Komatsu & Comin' & Lighttown Fidelity & 2011 & 178 \\
\hline 100 & Mo' Horizons & Pe Na Estrada (Radio Edit) & Agogo & 2008 & 178 \\
\hline 101 & Tony Bennett \& Lady Gaga & The Lady Is a Tramp & Sony Music Entertainment & 2011 & 179 \\
\hline 102 & One Direction & Kiss You & Syco/Columbia & 2012 & 180 \\
\hline 103 & Red Hot Chili Peppers & Can't Stop & Warner Music & 2002 & 182 \\
\hline 104 & The Pointer Sisters & I'm So Excited & Planet & 1982 & 184 \\
\hline 105 & Ok Go & Don't Ask Me & Capitol & 2002 & 186 \\
\hline 106 & Joan Jett \& The Blackhearts & I Love Rock 'N Roll & RAK & 1975 & 188 \\
\hline 107 & Wheatus & Teenage Dirtbag & Columbia & 2000 & 188 \\
\hline 108 & Absynthe Minded & Pretty Horny Flow & Abeille Musique & 2008 & 190 \\
\hline 109 & Eminem & Berzerk & $\begin{array}{l}\text { Aftermath Entertainment/Shady/ } \\
\text { Interscope }\end{array}$ & 2013 & 190 \\
\hline 110 & Macklemore \& Ryan Lewis & Thrift Shop (feat. Wanz) & Macklemore LLC/ADA & 2012 & 190 \\
\hline 111 & Roxette & The Look & EMI & 1988 & 190 \\
\hline 112 & Isbells & As Long As It Takes & Zeal & 2009 & 197 \\
\hline 113 & Beyonce & Crazy In Love (feat. Jay-Z) & Columbia/Music World & 2003 & 198 \\
\hline 114 & Rihanna & Pon de Replay & Def Jam & 2005 & 198 \\
\hline 115 & Gorillaz & $\begin{array}{l}\text { Stylo (Radio Edit) [feat. Mos Def \& } \\
\text { Bobby Womack] }\end{array}$ & Parlophone/Virgin & 2010 & 200 \\
\hline 116 & Wallace Vanborn & Atom Juggler & PIAS & 2010 & 200 \\
\hline 117 & Linkin Park & In the End & Warner Bros & 2000 & 210 \\
\hline
\end{tabular}

modification. D-Jogger was adapted to match the experimental protocol (detect running cadence, playback tempo-matched music to this reference, increase or decrease music tempo). The system logged all data and calculations in real time. Finally, the resulting auditory stimuli were sent back to the participant using a Sennheiser HDR130 audio transmitter (with a range of up to $100 \mathrm{~m}$ ). The participant perceived the music through Sennheiser HD60 headphones connected to the transmitter (attached to the upper arm). The delay due to the wireless audio transmission was negligible.

\section{Experimental Procedure and Set-up}

The experiment took place in the Flanders Sports Arena of Ghent, Belgium. In order to select motivational music adapted to each runner's personal taste, participants performed the Brunel Music Rating Inventory 2 (BMRI-2) test [48] at the start of the experiment. In this test, they were asked to rate all items of the music database by answering six questions about the motivational aspects of each song. Each item referred to an action, a time, a context, and a target (e.g. "The rhythm of this song would motivate me during a running exercise") [49]. Participants responded on a seven-point Likert scale anchored by 1 ("strongly disagree") and 7 ("strongly agree"). Afterwards, participants filled out a questionnaire on personal background, music education, and sports training. At the same time, for each participant individually, the 20 songs that had obtained the highest scores during the BMRI-2 test were loaded into the D-Jogger system.

Subsequently, participants were equipped with the iPods, the wireless headphone, and the audio transmitter. Each participant was asked to run on a 200-m running track for four laps continuously, for 12 times. 
Participants were instructed to run at their own comfortable tempo. No information was distributed concerning the real purpose of the experiment, and all participants ran in solo conditions. After each set of four laps, a break of approximately $5 \mathrm{~min}$ was introduced to enable the participant to recover sufficiently. Meanwhile, they were asked to indicate how heavy the effort had been during the exercise. This was rated on a Rating of Perceived Exertion (RPE) Scale [50], ranging from 6 ("no exertion at all") to 20 ("maximal exertion").

To get acquainted with the experimental set-up, the first set of four laps consisted of a practice set during which no music was played. Each of the 11 following four-lap sequences consisted of (1) a lap without music, (2) a lap with tempo-matched music, and (3) two laps with tempo-changed music. In the first lap, the participant ran at his/her self-paced cadence without musical accompaniment. In the second lap, music with a tempo matching the cadence assessed during the final $20 \mathrm{~s}$ of the previous lap was played. The musical stimulus consisted of the song that obtained the highest score during the BMRI-2 test with a tempo that differed maximally $5 \%$ from the running cadence of the participant. After the song was selected, its tempo was adjusted to exactly match the mean running cadence. Finally, during the third and fourth laps, the tempo of the music was adjusted according to one of the 11 tempo-changed conditions.

In each of the 11 four-lap sequences, a different condition was tested. During the two final laps with tempochanged music, the music tempo was adjusted to either $-3.00,-2.50,-2.00,-1.50,-1.00,0.00,+1.00,+1.50$, $+2.00,+2.50$, or $+3.00 \%$ of its original one, played during the second lap. This range was chosen since an average person can distinguish tempo variations from about $4 \%$ [51] and since the aim of this study was to test spontaneous or unintentional entrainment. The different conditions were randomized over the experiment in such a way that each participant performed all conditions but no participants performed the conditions in the same order. To ensure that they were not aware of the actual objective, participants filled out a questionnaire regarding their perception of the purpose of the experiment at the end. Responses did not indicate that they were aware of the experiment's real purpose.

\section{Data Analysis}

\section{Cadence Adaptation}

Running cadence was calculated using the iPods' acceleration data. In order to check the degree of cadence increase/decrease, running cadence (SPM) recorded during the laps with tempo-changed music (tempo-changed laps or TCL) was compared to the cadence captured during the lap with tempo-matched music (tempo- matched lap or TML) and will be further referred to as cadence adaptation. As the tempo was gradually shifting during that period, the first $5 \mathrm{~s}$ of the laps with tempo-changed music was discarded. The final $20 \mathrm{~s}$ of those laps was also ignored as participants possibly altered their running behaviour due to the anticipated ending of the final lap (e.g. slowing down or speeding up).

$$
\text { Cadence adaptation }(\%)=\frac{\operatorname{avg}\left(\text { SPM_TCL }_{-}\right)}{\operatorname{avg}(\text { SPM_TML })}
$$

\section{Entrainment}

A second measure of interest concerned the percentage of tempo-entrained steps during the laps with tempochanged music. A step taken in a tempo sufficiently close to the music tempo (max. $1 \%$ difference between SPM and BPM) at that specific moment is regarded as a tempo-entrained step. The tempo entrainment score is the percentage of tempo-entrained steps of the total amount of steps.

\section{Results}

\section{Running Cadence}

This study tested whether the changes in music tempo would affect running cadence. A Kolmogorov-Smirnov test (KS test) showed that the assumption of normality was met, $D(161)=0.04, p>.05$. A $11 \times 2 \times 2$ repeated measures ANOVA with tempo condition as withinsubject factor and gender and musical training as between-subject factors revealed a significant main effect of condition on cadence adaptation, $F(10,40)=6.50$, $p<.001$. Contrasts revealed a linear relation between condition and cadence adaptation, $F(1,4)=94.56$, $p<.001, r^{2}=.96$. The evolution of cadence adaptation over the different conditions is shown in Fig. 1.

There was no significant effect of gender, indicating rather similar levels of cadence adaptation for males and females, $F(1,4)=6.51, p=.06, r^{2}=.62$. However, there was a significant interaction effect between tempo condition and gender, $F(10,40)=3.40, p<.01$. As can be seen in Fig. 2, although for both males and females running cadence increased (or decreased) with increases (or decreases) in music tempo, these adjustments were more pronounced for women than for men. In addition, there was no significant effect of musical training, $F(1,4)=6.48$, $p=.06, r^{2}=.62$, which indicated that participants without musical training displayed similar levels of cadence adaptation as participants with a musical background. Finally, no significant interaction effect was found between musical training and tempo condition, $F(10,40)=1.79$, $p=.10$ (see Fig. 3). 


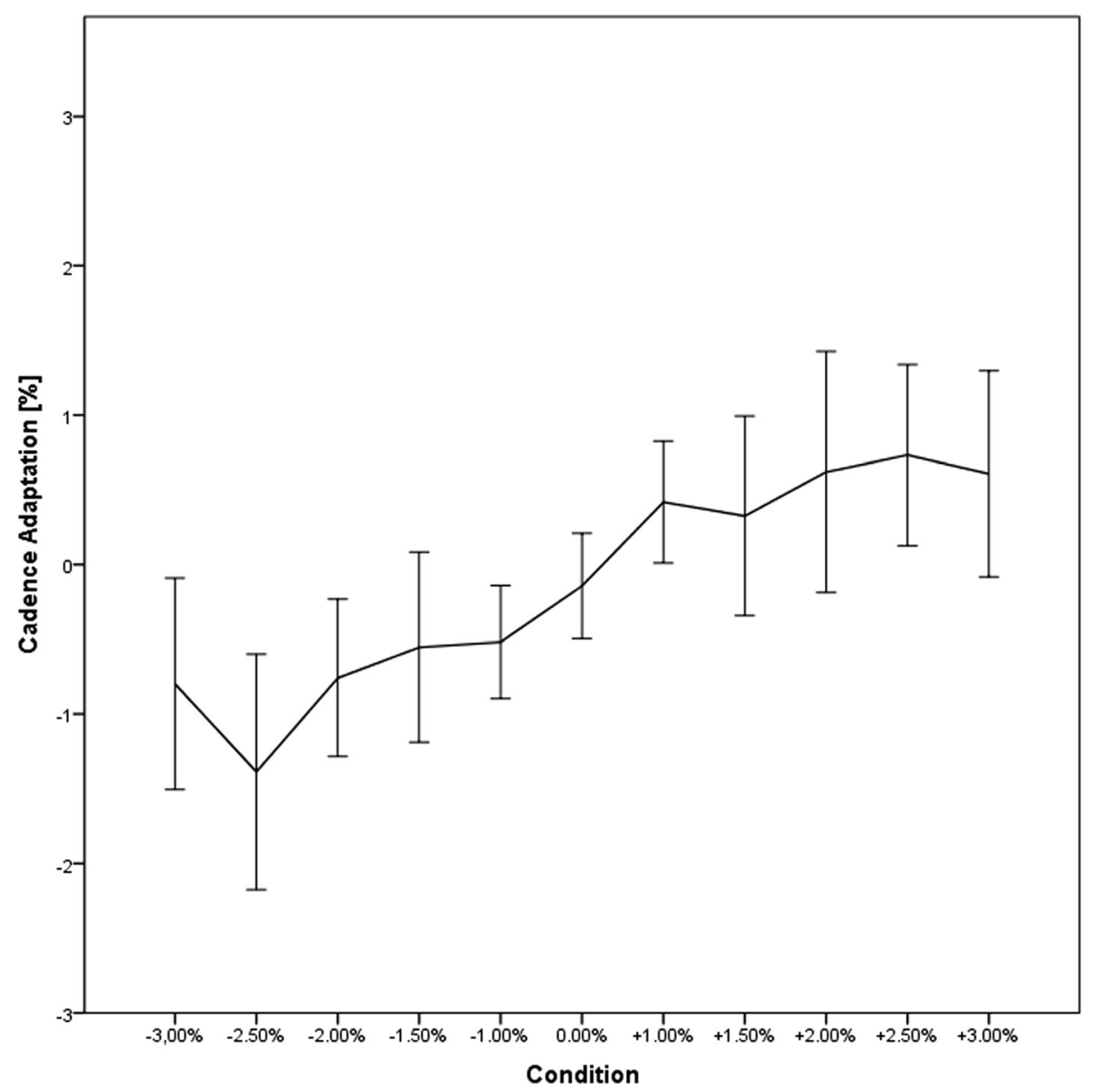

Fig. 1 Mean tempo and cadence adaptation for the different conditions. Data presented is mean $\pm \mathrm{SE}$

\section{Entrainment Basin}

In order to trace a possible basin for entrainment, the effect of the conditions on the level of tempo entrainment was tested. KS tests showed that the entrainment values were significantly non-normal, $D(161)=0.15, p<.001$. Friedman's ANOVA showed a significant effect of condition on tempo entrainment, $\chi^{2}(10)=19.27, \quad p<.05$. Wilcoxon tests were used to follow up this finding, and all conditions were compared against the control condition ( $0 \%$ of tempo change). A Bonferroni correction was applied, and all effects are thus reported at a .005 level of significance. It appeared that, compared to the control condition (Median $(\mathrm{Mdn})=74.25)$, tempo entrainment was significantly lower in the $+2.50 \%$ condition $((\mathrm{Mdn}=12.48)$, $\left.Z=-2.92, r^{2}=.53\right)$ and tended to be lower in the $+3.00 \%$ ( $\left.(\mathrm{Mdn}=14.01), Z=-2.41, p=.016, r^{2}=.36\right)$ and $-3.00 \%$ conditions $\left((\mathrm{Mdn}=6.97), Z=-2.48, p=.013, r^{2}=.38\right)$. Figure 4 represents the mean tempo entrainment for every single condition.

It is noteworthy that the entrainment basin did not differ significantly between females and males (see Fig. 5).
However, the mean level of entrainment appeared to be higher for females as compared to their male counterparts. When testing this assumption, a Mann-Whitney test indeed revealed significantly higher levels of tempo entrainment for female participants $(\mathrm{Mdn}=60.05)$ compared to their male counterparts $(\mathrm{Mdn}=39.10), U=10.00$, $Z=-2.28, p<.05, r^{2}=.32$. It was also tested whether a link between musical training and entrainment could be found. However, no significant difference was found between participants with $(\mathrm{Mdn}=50.73)$ or without musical background $(\mathrm{Mdn}=38.24)$ regarding their level of entrainment, $U=18.00, Z=-1.30, p=.19, r^{2}=.11$.

\section{Perceived Exertion}

It was also checked whether the level of entrainment could be related to the degree of perceived exertion. For this purpose, a two-tailed Spearman's correlation test was performed on entrainment values and ratings on the RPE scale. However, no significant relationship between perceived exertion and entrainment was found, $r_{\mathrm{s}}=-.04, p=.58$. 


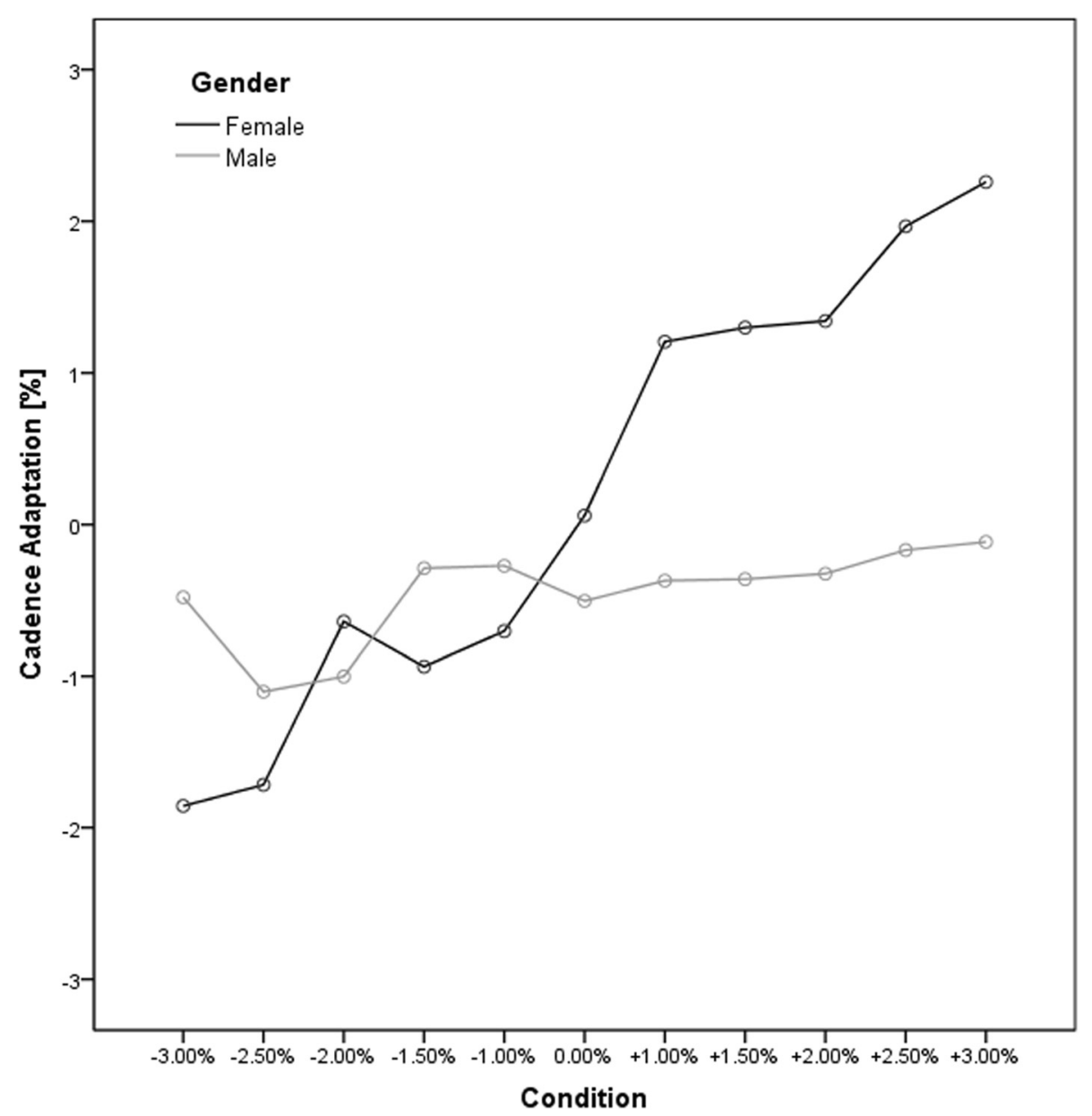

Fig. 2 Interaction plot of estimated marginal means calculated for cadence adaptation at both gender levels

\section{Discussion}

The aim of this study was to examine whether music tempo could serve as a means to influence running cadence. Results indeed unveiled a significant relationship between imperceptible alterations in music tempo, in proportion to recreational runners' self-paced running cadence, and cadence adaptation. In other words, faster music resulted in an increase, while slower music led to a decrease in running cadence. This effect can be explained through the idea of a sensorimotor mechanism that aligns footfall to musical beats. Adjustment of the footfalls to the beats relies on a phase-error correction mechanism of expected sensory outcomes [52]. Consequently, our study confirms results of previous research stressing the effect of music tempo on exercise performance $[8,11,41,53,54]$. This particular study also extends preceding research, as in this case, the effect on running cadence was tested using imperceptible changes in musical tempi with no explicit instructions regarding entrainment with the music. In contrast, in past research, participants were generally instructed to couple movement to music. Even if this was not the case, employed tempo variations usually proved to be too large to be unnoticeable. For example, Waterhouse, Hudson, and Edwards [41] compared cycling performance to normal, fast (increase of $10 \%$ ), and slow music (decrease of $10 \%$ ). Edworthy and Waring [8] examined treadmill-running behaviour when listening to music with a tempo of either 200 or 70 BPM, while Karageorghis et al. [53] employed tempi of 80,120 , and 140 BPM in their study on walking. In contrast, a maximum deviation of $3 \%$ from the original music tempo was implemented in this particular study, as the amount of variation in tempo that an average person can distinguish is situated around $4 \%$ [51]. Consequently, novel insights were presented in this study, as it was shown that recreational runners are able to adapt their running cadence (up to $2 \%$ of the original cadence) to tempo changes in music (up to $3 \%$ of the original tempo) without being aware of this attunement and without being instructed to do so. This finding supports the notion that an individual tends to synchronize spontaneously to an auditory rhythm 


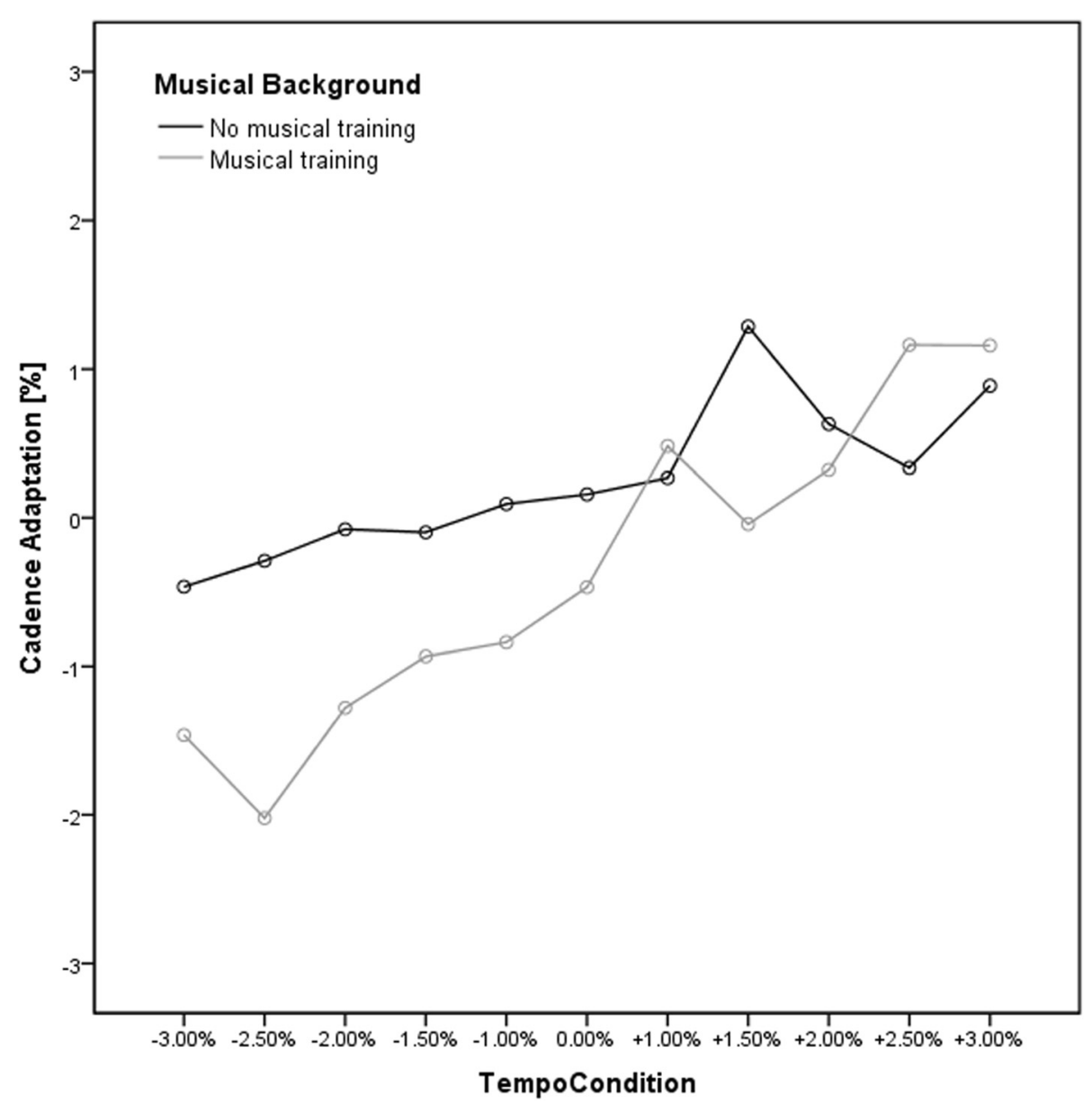

Fig. 3 Interaction plot of estimated marginal means calculated for cadence adaptation at both musical background levels

occurring in the environment $[37,39,52]$ and is in agreement with the natural predisposition of humans to respond to rhythmical qualities of music [34, 35].

It was also tested whether a basin for spontaneous entrainment of running cadence to music tempo could be found. Previous research has suggested that a range of period differences exists over which entrainment of movements of an individual with an environmental rhythm generally occurs and that beyond this range the occurrence of unintentional coordination is highly unlikely [33, 36-40]. Results indeed revealed a significant decrease in the level of entrainment in combination with increasing deviations from the original music tempo. The degree of entrainment with the tempo of the music dropped significantly as soon as tempo increases of $2.50 \%$ were introduced but also tended to drop at decreases of $3.00 \%$. This could be explained by the fact that when deviations (especially increases) from the original, self-selected, and thus comfortable running tempo got larger, the effort required from the runner increased and at a certain point probably required too much effort, resulting in significantly lower levels of entrainment. As such, our results are in line with the idea of an entrainment basin for spontaneous coordination [33, 36-40]. However, our findings also contrast with those of Mendonça et al. [54], showing that for uninstructed synchronization of walking to music, participants did not adapt their step frequency to music that differed 5 to $10 \%$ above and under their nominal step frequency, while they did adjust when synchronization was instructed. This could imply that a wider basin might be found for instructed entrainment to music tempo, while spontaneous entrainment occurs only when smaller deviations from the original tempo are introduced. But this is subject to some speculation and might benefit from further research.

Music is believed to only successfully distract from fatigue and discomfort when physiological awareness and perceived exertion are relatively low [19, 20, 22-24]. Therefore, in order to control for possible effects of 


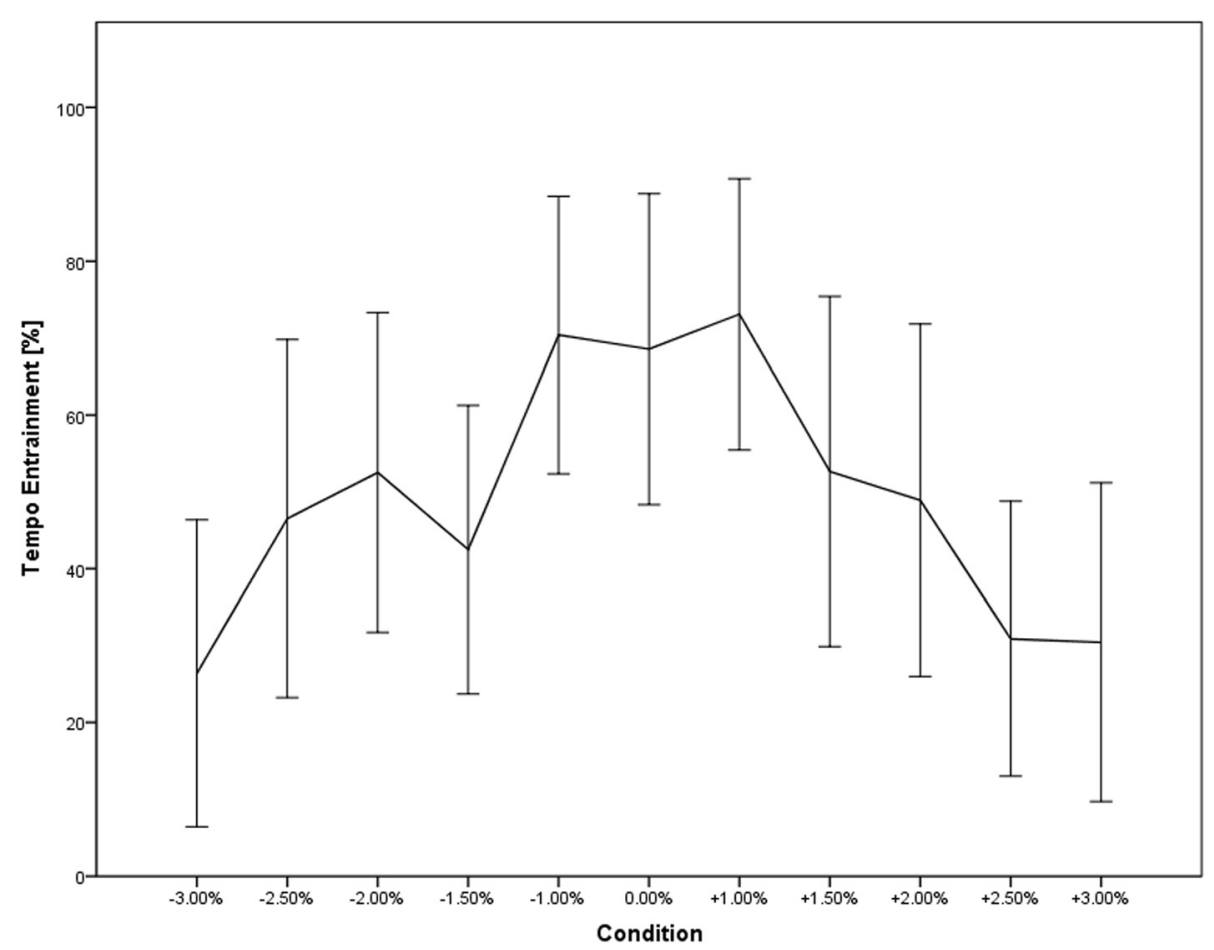

Fig. 4 Entrainment basin displaying mean tempo entrainment for the different conditions. Data presented is mean $\pm S E$

perceived exertion, after each set of four laps, a break of approximately $5 \mathrm{~min}$ was introduced. Besides, the relationship between the degree of perceived exertion and the level of entrainment was also examined in the analysis. Nevertheless, no significant relationship between perceived exertion and entrainment was found. This could be due to the fact that, in general, participants did not perceive the task as extremely light or exceptionally hard but mostly rated their perceived exertion as intermediate. A reason for this might be that runners ran at their comfort tempo and no large shifts in the tempo of the music were incorporated in the study, but it might also be partly due to the introduction of the breaks after each condition. Besides, most previous research demonstrating decreasing levels of influence of music on attentional processes at higher exercise intensities tested this effect using asynchronous music, e.g. $[19,20,22-24]$. Whether this also applies to synchronous music still remains rather unclear, although, in their study on the effect of synchronous music on treadmill running, Terry et al. [29] did indicate lower levels of perceived exertion, assessed at moderateto-high work intensities, for synchronous music compared to the no-music control. Yet, the magnitude of the differences in rating of perceived exertion proved to be rather small.

Another hypothesis referred to gender. We expected female participants to exhibit larger levels of entrainment in comparison with their male counterparts. Indeed, significantly higher levels of tempo entrainment were observed for females. In addition, although the effect of the music tempo on running cadence was unveiled for both males and females, changes in running cadence as a result of deviations in music tempi were more pronounced for female runners than for male ones, which suggests that women were more influenced by tempo changes than men. These findings resonate with the general belief that women are more responsive to musical stimuli $[11,41,34,55]$.

One should bear in mind that the current study focused on self-paced running, and thus, the type of exercise under study concerned one that is of low-to-moderate intensity. When studying activities with higher levels of intensity, music might not have a comparable effect on the exercisers' performance, as when high workloads are undertaken, the exerciser's attention could be shifted towards the painful or fatiguing effects of the exercise $[19,20,22-24]$. However, although most previous research on high-intensity exercise did not show any remarkable effects of music tempo, exemplary studies that have unveiled such effects do exist as well. In a study by Rendi, Szabo, and Szabo [10], for example, where exercisers were asked to perform a 500-m rowing sprint, in which physiological awareness is high, it was shown that fast-tempo music increased arousal and, in turn, performance, even during high-intensity sprints, while music with 


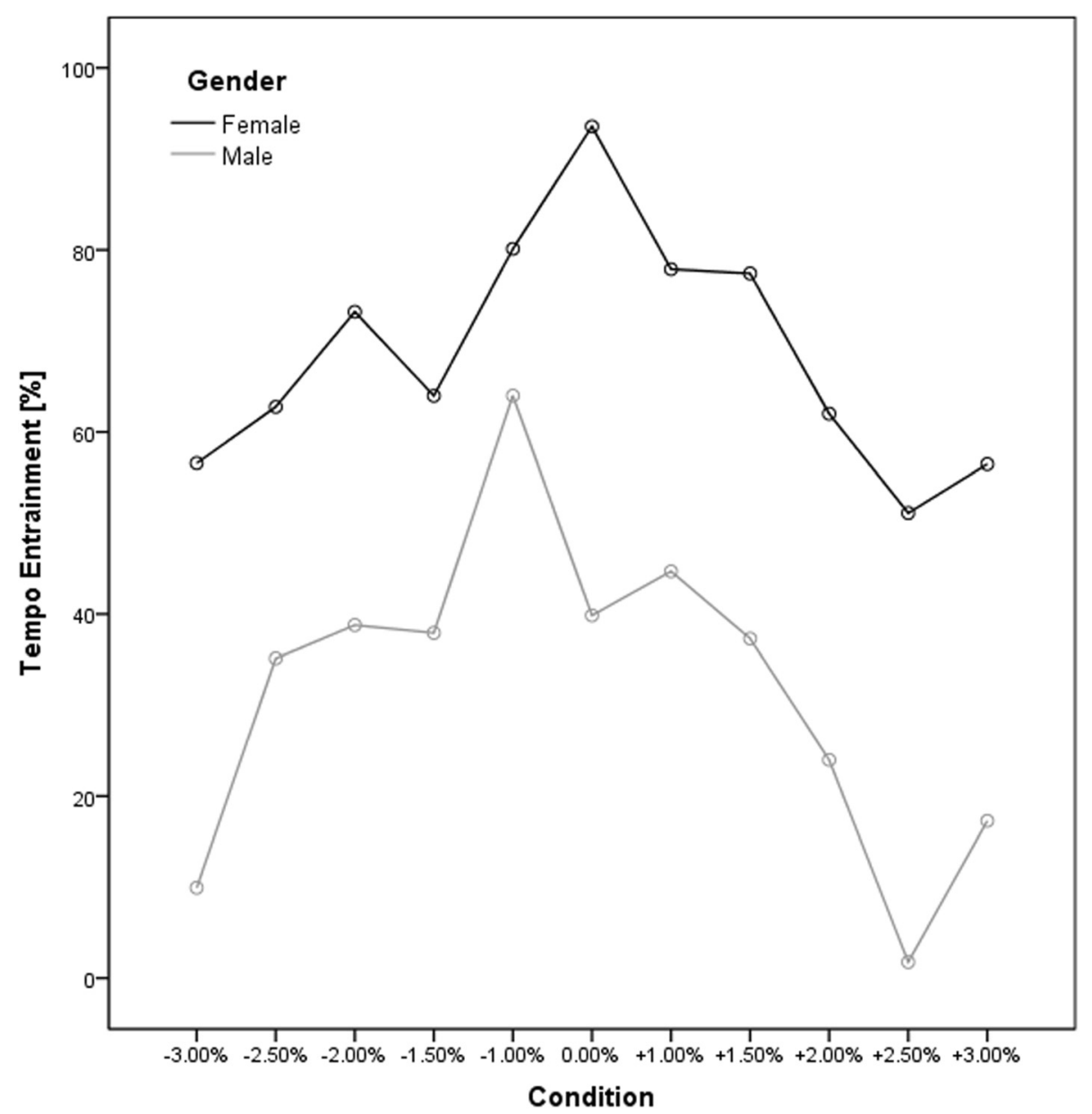

Fig. 5 Interaction plot of estimated marginal means calculated for tempo entrainment at both gender levels

a slow tempo did not generate such stimulating effects. Further exploration of the impact of music tempo on sport activities with high workloads would be beneficial.

It could also be questioned whether spontaneous, thus uninstructed, entrainment is generally more beneficial with regard to exercise performance than instructed entrainment. It could be suggested that when synchronization is spontaneous, it may require less attentional resources, thus leading to even more important benefits (e.g. leaving free attentional resources to realize other tasks). Besides, exercise training could be simplified when instruction would prove to be redundant. On the other hand, it has been indicated that instructed synchronization is a form of active attentional manipulation, which has been shown to have more positive effects, at least in the form of perceived exertion and exercise efficiency $[12,28]$. However, as this question has not been solved yet, the discussion whether spontaneous synchronization is more beneficial compared to instructed (or even imposed) synchronization should be unravelled in future studies.

In this particular study, recreational runners were tested. However, since music is believed to be more beneficial for recreational compared to trained exercisers [56], different results might have been obtained if competitive runners were tested. Previous research on treadmill running indicated that less trained exercisers might depend to a greater extent on the positive feeling states generated by music, while trained exercisers generally tend to focus on the tasks and specifics of their training $[57,58]$. Furthermore, as (either recreational or professional) runners do not typically tend to run distances of $800 \mathrm{~m}$ consecutively, interrupted by short brakes, it might be interesting to investigate whether the effect of music tempo is sustained over the course of longer, interrupted distances. Whether the entrainment basin for recreational runners would differ from that of professional runners and whether its effects are sustained over longer distances could be tested in future research. 


\section{Conclusions}

To conclude, it was unveiled that music tempo could serve as an unprompted means to re(shape) running cadence of recreational runners. This influence was shown to have a certain range, which suggests that maximal effects of music tempo can only be obtained up to a certain level of tempo change and proved to be stronger for female compared to male runners. As modifying step rate may prove beneficial in the prevention and treatment of common runningrelated injuries, this novel finding could be especially relevant for treatment purposes, such as exercise prescription and gait retraining.

\section{Additional file}

Additional file 1: Validity and reliability of the testing equipment. During development of the D-Jogger system, several tests/experiments/ pilots were conducted to verify and correct individual components and the final device (D-Jogger system + iPod sensors).

\section{Competing Interests}

The authors declare that they have no competing interests.

\section{Authors' Contributions}

Conceived the study: EVD, BM, JB, MD, and ML. Performed the experiments: EVD, BM, JB, and EC. Analysed the data: EVD, BM, and SDB. Wrote and/or revised the paper: EVD and BM. All authors read and approved the final manuscript.

\section{Acknowledgements}

The authors wish to thank the Flanders Sports Arena of Ghent, for making it possible to use their running track. The authors also acknowledge BeatHealth (contract \#610633), a collaborative project funded by the European Commission under the Seventh Framework Programme, and the Methusalem project, awarded by the Flemish Government, for funding this study.

\section{Author details}

${ }^{1}$ IPEM, Department of Arts, Music and Theatre Sciences, Ghent University, Technicum Blok 2, Sint-Pietersnieuwstraat 41, Ghent, Belgium. ²EuroMov, Movement 2 Health Laboratory (M2H), University of Montpellier, 700 Avenue du Pic Saint Loup, Montpellier, France.

Received: 28 November 2014 Accepted: 2 July 2015

Published online: 14 July 2015

\section{References}

1. van Gent RN, Siem D, van Middelkoop M, van Os AG, Bierma-Zeinstra SM, Koes BW. Incidence and determinants of lower extremity running injuries in long distance runners: a systematic review. Br J Sports Med. 2007:41:469-80.

2. Taunton JE, Ryan MB, Clement DB, McKenzie DC, Lloyd-Smith DR, Zumbo $\mathrm{BD}$. A retrospective case-control analysis of 2002 running injuries. $\mathrm{Br} J$ Sports Med. 2002;36:95-101.

3. Ferber R, Noehren B, Hamill J, Davis I. Competitive female runners with a history of iliotibial band syndrome demonstrate atypical hip and knee kinematics. J Orthop Sports Phys Ther. 2010;40:52-8.

4. Noehren B, Davis I, Hamill J. ASB clinical biomechanics award winner 2006 prospective study of the biomechanical factors associated with iliotibial band syndrome. Clin Biomech. 2007;22:951-6.

5. Heiderscheit BC, Chumanov ES, Michalski MP, Wille CM, Ryan MB. Effects of step rate manipulation on joint mechanics during running. Med Sci Sports Exerc. 2011;43:296-302.

6. Priest $\mathrm{DL}$, Karageorghis $\mathrm{Cl}$. A qualitative investigation into the characteristics and effects of music accompanying exercise. Eur Phys Educ Rev. 2008;14:347-66.
7. Yamashita S, Twai K, Aktmoto T, Sugawara J, Kono I. Effects of music during exercise on RPE, heart rate and the autonomic nervous system. J Sports Med Phys Fitness. 2006:46:425-30

8. Edworthy J, Waring $H$. The effects of music tempo and loudness level on treadmill exercise. Ergonomics. 2006;49:1597-610.

9. Shaulov N, Lufi D. Music and light during indoor cycling. Percept Motor Skills. 2009;108:597-607.

10. Rendi M, Szabo A, Szabó T. Performance enhancement with music in rowing sprint. Sport Psychol. 2008;22:175-82.

11. Priest DL, Karageorghis Cl, Sharp NCC. The characteristics and effects of motivational music in exercise settings: the possible influence of gender, age, frequency of attendance, and time of attendance. J Sports Med Phys Fitness. 2004;44:77-86.

12. Lim HBT, Karageorghis Cl, Romer LM, Bishop DT. Psychophysiological effects of synchronous versus asynchronous music during cycling. Med Sci Sports. 2014;46:407-13.

13. Särkämö T, Tervaniemi M, Laitinen S, Forsblom A, Soinila S, Mikkonen M, et al. Music listening enhances cognitive recovery and mood after middle cerebral artery stroke. Brain. 2008;131:866-76.

14. Atkinson $G$, Wilson D, Eubank M. Effects of music on work-rate distribution during a cycling time trial. Int J Sports Med. 2004;25:611-5.

15. Hsu DY, Huang L, Nordgren LF, Rucker DD, Galinsky AD. The music of power: perceptual and behavioral consequences of powerful music. Soc Psychol Personal Sci. 2014; doi:10.1177/1948550614542345

16. Simpson SD, Karageorghis Cl. The effects of synchronous music on 400-m sprint performance. J Sports Sci. 2006;24:1095-102.

17. Styns F, van Noorden L, Moelants D, Leman M. Walking on music. Hum Mov Sci. 2007;26:769-85.

18. Bood RJ, Nijssen M, van der Kamp J, Roerdink M. The power of auditory-motor synchronization in sports: enhancing running performance by coupling cadence with the right beats. Plos One. 2013; doi:10.1371/journal.pone.0070758

19. Rejeski WJ. Perceived exertion: an active or passive process? J Sport Exerc Psychol. 1985;7:371-8.

20. Nethery VM. Competition between internal and external sources of information during exercise: influence on RPE and the impact of the exercise load. J Sports Med Phys Fitness. 2002;42:172-8.

21. Tenenbaum G. A social-cognitive perspective of perceived exertion. In: Tenenbaum G, Eklund R, editors. Handbook of sport psychology. 3rd ed. Hoboken: Wiley; 2007. p. 560-77.

22. Tenenbaum $\mathrm{G}$. The study of perceived and sustained effort: concepts, research findings, and future directions. In: Hackfort D, Duda J, Lidor R, editors. Handbook of research on applied sport psychology. Morgantown: Fitness Information Technology; 2005. p. 335-49.

23. Razon S, Basevitch I, Land W, Thompson B, Tenenbaum G. Perception of exertion and attention allocation as a function of visual and auditory conditions. Psychol Sport Exerc. 2009;10:636-43.

24. Hutchinson JC, Tenenbaum G. Attention focus during physical effort: the mediating role of task intensity. Psychol Sport Exerc. 2007:8:233-45.

25. Karageorghis $\mathrm{Cl}$. The scientific application of music in sport and exercise. In: Lane AM, editor. Sport and exercise psychology. London: Hodder Education; 2008. p. 109-37.

26. Cohen SL, Paradis C, LeMura LM. The effects of contingent-monetary reinforcement and music on exercise in college students. J Sport Behav. 2007:30:146-60.

27. Elliott D, Carr $S$, Orme D. The effect of motivational music on sub-maximal exercise. Eur J Sport Sci. 2005;5:97-106.

28. Karageorghis Cl, Mouzourides D, Priest DL, Sasso T, Morrish D, Whalley C. Psychophysical and ergogenic effects of synchronous music during treadmill walking. J Sport Exerc Psychol. 2009;31:18-36.

29. Terry PC, Karageorghis Cl, Mecozzi Saha A, D'Auria S. Effects of synchronous music on treadmill running among elite triathletes. J Sci Med Sport. 2012;15:52-7.

30. Kenyon GP, Thaut MH. Rhythm-driven optimization of motor control. Recent Res Dev Biomech. 2003;1:29-47.

31. Smoll FL, Schultz RW. Accuracy of motor behaviour in response to preferred and nonpreferred tempos. J Hum Mov Stud. 1982;8:123-38.

32. Rossignol S, Melvill-Jones G. Audiospinal influences in man studied by the $\mathrm{H}$-reflex and its possible role in rhythmic movement synchronized to sound. Electroencephalogr Clin Neurophysiol. 1976;41:83-92.

33. Richardson MJ, Marsh KL, Schmidt RC. Effects of visual and verbal interaction on unintentional interpersonal coordination. J Exp Psychol: Human Percept Perform. 2005;31:62-79. 
34. Karageorghis Cl, Terry PC, Lane AM. Development and validation of an instrument to assess the motivational qualities of music in exercise and sport: the Brunel Music Rating Inventory. J Sports Sci. 1999;17:713-24.

35. Large EW. On synchronizing movements to music. Hum Mov Sci. 2000;19:527-66.

36. von Holst E. Relative coordination as a phenomenon and as a method of analysis of central nervous system function. In: Martin R, editor. The collected papers of Erich von Holst, The behavioral physiology of animal and man, vol. 1. Coral Gables: University of Miami Press; 1973. p. 33-135.

37. Lopresti-Goodman SM, Richardson MJ, Silva PL, Schmidt RC. Period basin of entrainment for unintentional visual coordination. J Mot Behav. 2008:40:3-10.

38. Schmidt RC, Richardson MJ. Dynamics of interpersonal coordination. Berlin: Springer; 2008

39. Schmidt RC, Richardson MJ, Arsenault CA, Galantucci B. Visual tracking and entrainment to an environmental rhythm. J Exp Psychol: Human Percept Perform. 2007:33:860-70.

40. Strogatz SH. Nonlinear dynamic and chaos: with applications to physics, biology, chemistry, and engineering. Cambridge: Perseus Books; 1994.

41. Waterhouse J, Hudson P, Edwards B. Effects of music tempo upon submaximal cycling performance. Scand I Med Sci Sports. 2010;20:662-9.

42. Kelso JAS. Dynamic patterns: the self-organization of brain and behavior. Cambridge: MIT Press; 1995.

43. Van Dyck E, Moelants D, Demey M, Deweppe A, Coussement P, Leman M. The impact of the bass drum on human dance movement. Music Percept. 2013;30:349-59.

44. Faul F, Erdfelder E, Lang AG, Buchner A. G*Power 3: a flexible statistical power analysis program for the social, behavioral, and biomedical sciences. Behav Res Methods. 2007;39:175-91.

45. Karageorghis $\mathrm{Cl}$, Terry PC, Lane AM, Bishop DT, Priest DL. The BASES expert statement on use of music in exercise. J Sports Sci. 2012:30:953-6.

46. Dixon S. Evaluation of the audio beat tracking system BeatRoot. J New Music Res. 2007;36:39-50

47. Moens B, Muller C, van Noorden L, Franek M, Celie B, Boone J, et al. Encouraging spontaneous synchronisation with DJogger, an adaptive music player that aligns movement with music. Plos One. In press.

48. Karageorghis Cl, Priest DL, Terry PC, Chatzisarantis NLD, Lane AM. Development and validation of an instrument to assess the motivational qualities of music in exercise: the Brunel Music Rating Inventory-2. J Sports Sci. 2006:24:899-909.

49. Ajzen I, Fishbein M. Attitude-behavior relations: a theoretical analysis and review of empirical research. Psychol Bull. 1977;84:888-918.

50. Borg G. Borg's perceived exertion and pain scales. Human Kinetics: Champaign; 1998.

51. Levitin D. This is your brain on music: the science of a human obsession New York: Dutton; 2006.

52. Repp BH, Su YH. Sensorimotor synchronization: a review of recent research (2006-2012). Psychon Bull Rev. 2013;20:403-52.

53. Karageorghis C, Jones L, Low D. Relationship between exercise heart rate and music tempo preference. Res Quart Exerc Sport. 2006;77:240-50.

54. Mendonça C, Oliveira M, Fontes $L$, Santos J. The effect of instruction to synchronize over step frequency while walking with auditory cues on a treadmill. Hum Mov Sci. 2014;33:33-42.

55. Pellett TL. Children's stereotypical perceptions of physical activities: a K-12 analysis. Percept Motor Skills. 1994;79:1128-30.

56. Karageorghis Cl, Priest DL. Music in the exercise domain: a review and synthesis (Part II). Int Rev Sport Exerc Psychol. 2012;5:67-84.

57. Brownley KA, McMurray RG, Hackney AC. Effects of music on physiologica and affective responses to graded treadmill exercise in trained and untrained runners. Int J Psychophysiol. 1995;19:193-201.

58. Mohammadzadeh $\mathrm{H}$, Tartibiyan B, Ahmadi A. The effects of music on the perceived exertion rate and performance of trained and untrained individuals during progressive exercise. Facta Univ Phys Educ Sport. 2008;6:67-74.

\section{Submit your manuscript to a SpringerOpen ${ }^{\circ}$ journal and benefit from:}

- Convenient online submission

- Rigorous peer review

- Immediate publication on acceptance

- Open access: articles freely available online

- High visibility within the field

- Retaining the copyright to your article

Submit your next manuscript at $\gg$ springeropen.com 